\title{
HUBUNGAN KARAKTERISTIK SOSIAL EKONOMI DENGAN PARTISIPASI PETANI DALAM GERAKAN PENERAPAN PENGELOLAAN TANAMAN TERPADU (GP-PTT) KEDELAI DI KECAMATAN KEDAWUNG KABUPATEN SRAGEN
}

\author{
Sandra Kasaniva Adwiyana ${ }^{1)}$, Agung Wibowo ${ }^{1)}$, Arip Wijianto ${ }^{1)}$ \\ ${ }^{1)}$ Program Studi Agribisnis, Fakultas Pertanian, Universitas Sebelas Maret \\ Email : kasanivasandra@gmail.com
}

\begin{abstract}
This research aim to analyse social economy characteristics of farmers, to analyse farmers participation, and to analyse correlation between social economy characteristics of farmers with participation of farmers in GP-PTT Soybean Plants at Kedawung District, Sragen Regency. Basic methods for this research is explanatory. Research was conducted at Kedawung District in consideration of Kedawung District is a district in Sragen regency which take part in GP-PTT Soybean Plants activity with an area of 1,000 hectare. Data analysis which used is Rank Spearman correlation aim to find out the relation of Social Economy characteristic of farmers with farmers participation in the activity of GP-PTT Soybean Plants. The sampling method that applied in this research is proportional random sampling. Numbers of respondents researched in this research are 50 respondents. Analysis to find out level of significance used t test. The social economy characteristics of farmers in this research are age, formal education, non-formal education, income, farm size, and farming experience. Participations of farmers in this research are participations in planning, execution, monitoring and evaluation, as well as the utilization of the results. The results of this research shows that there is very significance correlation between non-formal education with level of participation in planning, monitoring, and evaluation. There is a very significance correlation between farming experience with level of participation in planning.
\end{abstract}

Keywords: GP-PTT Soybean Plants, Participation of Farmers, Social Economy Characteristics of Farmers

\section{PENDAHULUAN}

Pembangunan pertanian diarahkan untuk meningkatkan produksi pertanian. Selama dua dekade terakhir laju peningkatan produksi pangan nasional tidak mampu mengimbangi peningkatan kebutuhan pangan masyarakat. Hal tersebut tercermin dari terus meningkatnya impor produk pangan, termasuk beras, jagung, dan kedelai. Sebagai upaya mewujudkan kedaulatan dan ketahanan pangan nasional, Presiden RI Joko Widodo bertekad untuk mewujudkan Program Upaya Khusus Peningkatan Padi, Jagung dan Kedelai (UPSUS PAJALE) yang ditargetkan tercapai pada tahun 2017. Program UPSUS PAJALE diluncurkan pada April 2015 dengan tujuan Indonesia akan mampu memenuhi kebutuhan pangannya sendiri dalam tiga tahun.

GP-PTT merupakan salah satu kegiatan penunjang program UPSUS PAJALE. Pelaksanaan GP-PTT dimaksudkan untuk meningkatkan produktivitas, pendapatan petani dan kelestarian lingkungan. Dalam operasionalisasinya. GP-PTT menerapkan prinsip PTT yang mencakup empat unsur, yaitu integrasi, interaksi, dinamis, dan partisipatif (Direktorat Jendral Tanaman Pangan, 2015). Salah satu komoditas yang perlu ditingkatkan adalah kedelai. Di Indonesia kebutuhan akan kedelai terus meningkat dari tahun ke tahun, seiring dengan meningkatnya jumlah penduduk. Rata-rata kebutuhan kedelai setiap tahun mencapai $\pm 2,2$ juta ton biji kering, akan tetapi kemampuan produksi dalam negeri berdasarkan ARAM (Angka Ramalan) II tahun 2014 baru mampu memenuhi sebanyak 921.336 ton atau $40,06 \%$. Untuk memenuhi kekurangan tersebut harus dipenuhi dari impor yang menyebabkan berbagai kerugian bagi Indonesia. Untuk itu, pada tahun 2015 Kementerian Pertanian memberikan dana Bantuan Sosial (Bansos) pengadaan paket sarana produksi untuk kegiatan GP-PTT Kedelai (Direktorat Jendral Tanaman Pangan, 2015).

Kabupaten Sragen merupakan salah satu kabupaten yang mendapatkan kegiatan GPPTT Komoditas Kedelai seluas $1.000 \mathrm{Ha}$. Kabupaten Sragen memiliki 20 kecamatan, 
namun hanya 11 kecamatan saja yang melaksanakan kegiatan GP-PTT Kedelai salah satunya adalah Kecamatan Kedawung. Salah satu kunci utama keberhasilan GP-PTT kedelai adalah partisipasi petani. Tanpa adanya partisipasi petani maka kegiatan tersebut tidak akan berhasil karena petani merupakan pelaku utama dalam program pembangunan pertanian. Wiwik (1998) mengemukakan adanya beberapa faktor yang berhubungan dengan tingkat partisipasi. Diantaranya adalah karakteristik sosial ekonomi petani. Karakteristik sosial ekonomi petani merupakan tolak ukur dalam berpartisipasi. Tujuan dari penelitian ini adalah: (1) Menganalisis karakteristik sosial ekonomi petani (2) Menganalisis partisipasi petani, dan (3) Menganalisis hubungan antara karakteristik sosial ekonomi petani dengan partisipasi petani dalam kegiatan Gerakan Penerapan Pengelolaan Tanaman Terpadu (GP-PTT) kedelai di Kecamatan Kedawung Kabupaten Sragen.

\section{METODE PENELITIAN}

Metode dasar yang digunakan dalam penelitian ini adalah metode explanatory (penjelasan), sedangkan teknik pelaksanaan penelitian ini menggunakan teknik survei. Menurut Singarimbun dan Effendi (2006), untuk data yang sama peneliti menjelaskan hubungan kausal antara variabel-variabel melalui pengujian hipotesa, maka penelitian tersebut dinamakan penelitian hipotesa atau penelitian penjelasan (explanatory research).

Penelitian dilakukan di Kecamatan Kedawung dengan pertimbangan bahwa Kecamatan Kedawung merupakan salah satu kecamatan di Kabupaten Sragen yang mengikuti kegiatan GP-PTT kedelai seluas 1.000 hektar yang memiliki produktivitas GPPTT kedelai tertinggi diantara kecamatan lainnya yang melaksanakan kegiatan GP-PTT kedelai di Kabupaten Sragen. Kecamatan Kedawung terdiri dari 10 desa, namun hanya 3 desa yang bersedia mengikuti kegiatan GPPTT Kedelai, dengan jumlah kelompok tani yang mengikuti sebanyak 18 kelompok tani.

Penarikan sampel dalam penelitian ini dilakukan dengan menggunakan metode proportional random sampling. Proportional random sampling. yaitu pengambilan sampel dengan menetapkan jumlah tergantung besar kecilnya sub populasi atau kelompok yang akan diwakilinya (Mardikanto, 2006). Jumlah sampel dalam penelitian ini adalah sebanyak 50 responden. Penentuan jumlah petani responden dari masing-masing kelompok tani ditentukan dengan menggunakan rumus sebagai berikut:

$n i=\frac{n k}{N} n$

Keterangan: ni: jumlah responden, nk: jumlah petani dari masing-masing kelompok tani, $\mathbf{N}$ : jumlah populasi petani, $\mathbf{n}$ : jumlah petani yang diambil yaitu sebanyak 50 petani adalah

Metode Analisis Data yang digunakan

1. Untuk menganalisis karakteristik sosial ekonomi petani dan tingkat partisipasi petani dalam GP-PTT kedelai, digunakan skala likert yang kemudian dibuat kelas panjang interval yang dikategorikan menjadi tinggi, sedang, dan rendah. Untuk dapat mengukur kategori tersebut dihitung dengan menggunakan rumus lebar interval (i) sebagai berikut:

Lebar interval $=$

$\frac{\sum \text { skor tertinggi }-\sum \text { skor terendah }}{\sum \text { kelas }}$

2. Untuk menganalisis hubungan karakteristik sosial ekonomi dengan partisipasi petani dalam kegiatan GP-PTT kedelai diukur menggunakan median score dan dianalisis dengan uji korelasi Rank Spearman (rs). Menurut Siegel (1997) rumus koefisien korelasi Rank Spearman (rs) adalah sebagai berikut:

$\mathbf{r s}=1-\frac{6 \sum_{i=1} d i^{2}}{\mathrm{~N}^{3}-\mathrm{N}}$

Keterangan $: \mathbf{r}_{\mathrm{s}}=$ koefisien korelasi rang spearman, $\mathbf{N}=$ jumlah sampel petani, $\mathbf{d i}=$ selisih ranking antar variable

3. Untuk menguji tingkat signifikansi hubungan digunakan uji t karena sampel yang diambil lebih dari $10(\mathrm{~N}>10)$ dengan tingkat kepercayaan 95\% dengan rumus (Siegel, 1997) :

$\mathbf{t}=r_{s} \sqrt{\frac{N-2}{1-(\mathrm{rs})^{2}}}$ 
HASIL DAN PEMBAHASAN

\section{Gerakan Penerapan Pengelolaan Tanaman Terpadu (GP-PTT) Kedelai}

GP-PTT adalah program nasional untuk meningkatkan produksi kedelai, melalui pendekatan gerakan atau anjuran secara massal kepada petani/kelompok tani untuk melaksanakan teknologi Pengelolaan Tanaman Terpadu (PTT) dalam mengelola usaha tani kedelai, dengan tujuan meningkatkan produktivitas, pendapatan petani dan kelestarian lingkungan. Sasaran pelaksanaan GP-PTT kedelai tahun 2015 seluas 1.000 ha yang tersebar di 11 kecamatan di Kabupaten Sragen. Kecamatan Kedawung memiliki luas lahan terluas untuk kegiatan GP-PTT kedelai yaitu seluas 290 ha yang terbagi atas tiga desa. Tiga desa tersebut adalah Desa Bendungan seluas 50 ha, Desa Wonokerso seluas 50 ha, dan Desa Pengkok seluas 190 ha.
Pemerintah memberikan bantuan berupa sarana produksi, biaya pertemuan kelompok dan pendampingan petugas penyuluh/mantri tani maupun pendamping lainnya untuk memfasilitasi pelaksanaan GP-PTT kedelai. Sarana produksi yang diberikan yaitu benih dengan varietas grobogan, pupuk an organik NPK dan SP-36 bersubsidi yang pembeliannya melalui Rencana Definitif Kebutuhan Kelompok (RDKK) sesuai peraturan yang berlaku, pupuk organik, pupuk hayati (Rhizobium) 200-250 gram/ha, pestisida organik/anorganik. Bantuan sarana produksi kegiatan GP-PTT, diberikan langsung kepada kelompok tani peserta GP-PTT dalam bentuk transfer uang, dengan nilai uang sebesar Rp. 1.804.000,- per hektar. Alokasi dana bantuan sarana produksi kegiatan GP-PTT kedelai tahun 2015 dapat dilihat pada tabel berikut:

Tabel 1. Alokasi dana bantuan kegiatan GP-PTT kedelai tahun 2015

\begin{tabular}{clccr}
\hline No. & \multicolumn{1}{c}{ Saprodi } & Volume & $\begin{array}{c}\text { Harga Satuan } \\
(\mathbf{R p})\end{array}$ & $\begin{array}{c}\text { Total Biaya per 1 Ha } \\
(\mathbf{R p})\end{array}$ \\
\hline 1. & Benih & $50 \mathrm{Kg}$ & $15.200 / \mathrm{kg}$ & 760.000 \\
2. & Pupuk NPK & $100 \mathrm{Kg}$ & $2.300 / \mathrm{kg}$ & 230.000 \\
3. & Pupuk SP-36 & $50 \mathrm{Kg}$ & $2.000 / \mathrm{kg}$ & 100.000 \\
4. & Pupuk Organik & $1 \mathrm{paket}$ & $250.000 / \mathrm{paket}$ & 250.000 \\
5. & Pupuk Hayati Rhizobium & $1 \mathrm{paket}$ & $120.000 / \mathrm{paket}$ & 120.000 \\
6. & Pestisida Organik/An Organik & 2 liter & $120.000 /$ liter & 240.000 \\
7. & Pertemuan Kelompok & $2 \mathrm{kali}$ & $52.000 /$ paket & 104.000 \\
\hline \multicolumn{3}{r}{ Total Biaya Per Hektar } \\
\hline
\end{tabular}

Sumber: Direktorat Jendral Tanaman Pangan, 2015.

\section{Karakteristik Sosial Ekonomi Petani}

Berdasarkan Tabel 2 dapat diketahui bahwa distribusi umur petani secara keseluruhan termasuk dalam kategori tinggi (72\%). Umur petani pada saat dilakukan penelitian berumur 55-60 tahun. Petani berada pada usia produktif dan masih aktif dalam melakukan kegiatan usahatani. Petani yang berusia produktif cenderung lebih mudah menerima inovasi baru dan cenderung potensial untuk lebih meningkatkan peran sertanya dalam suatu kegiatan. Sedangkan petani memulai usahatani kedelai pada umur > 35 tahun. Petani memulai usahataninya di usia yang produktif sehingga responden memiliki semangat yang tinggi untuk mengikuti kegiatan GP-PTT kedelai.

Berdasarkan Tabel 2 dapat diketahui bahwa distribusi tingkat pendidikan petani secara keseluruhan termasuk dalam kategori rendah (42\%). Petani hanya menempuh pendidikannya selama 6 tahun, yaitu sampai tamat SD. Hal ini disebabkan karena keluarga petani kekurangan biaya untuk melanjutkan pendidikan kejenjang yang lebih tinggi sehingga petani lebih memilih untuk melanjutkan usahatani keluarganya. 
Tabel 2. Karakteristik sosial ekonomi petani

\begin{tabular}{|c|c|c|c|c|c|}
\hline No. & $\begin{array}{c}\text { Karakteristik } \\
\text { Sosial Ekonomi }\end{array}$ & Kategori & Interval & $\begin{array}{c}\text { Jumlah } \\
\text { Responden }\end{array}$ & $\begin{array}{c}\text { Persentase } \\
(\%)\end{array}$ \\
\hline \multirow[t]{5}{*}{1.} & Umur & Sangat Tinggi & $8,5-10$ & 12 & 24,00 \\
\hline & & Tinggi & $6,9-8,4$ & 36 & 72,00 \\
\hline & & Sedang & $5,3-6,8$ & 1 & 2,00 \\
\hline & & Rendah & $3,7-5,2$ & 1 & 2,00 \\
\hline & & Sangat Rendah & $2-3,6$ & $\mathbf{0}$ & 0,00 \\
\hline \multirow[t]{5}{*}{2.} & Pendidikan Formal & Sangat Tinggi & $8,5-10$ & 1 & 2,00 \\
\hline & & Tinggi & $6,9-8,4$ & 18 & 36,00 \\
\hline & & Sedang & $5,3-6,8$ & 3 & 6,00 \\
\hline & & Rendah & $3,7-5,2$ & 21 & 42,00 \\
\hline & & Sangat Rendah & $2-3,6$ & 7 & 14,00 \\
\hline \multirow[t]{5}{*}{3.} & Pendidikan Non Formal & Sangat Tinggi & $8,5-10$ & 0 & 0,00 \\
\hline & & Tinggi & $6,9-8,4$ & 10 & 20,00 \\
\hline & & Sedang & $5,3-6,8$ & 40 & 80,00 \\
\hline & & Rendah & $3,7-5,2$ & 0 & 0,00 \\
\hline & & Sangat Rendah & $2-3,6$ & 0 & 0,00 \\
\hline \multirow[t]{5}{*}{4.} & Pendapatan & Sangat Tinggi & $12,7-15$ & 2 & 4,00 \\
\hline & & Tinggi & $10,3-12,6$ & 27 & 54,00 \\
\hline & & Sedang & $7,9-10,2$ & 8 & 16,00 \\
\hline & & Rendah & $5,5-7,8$ & 6 & 12,00 \\
\hline & & Sangat Rendah & $3-5,4$ & 7 & 14,00 \\
\hline \multirow[t]{5}{*}{5.} & Luas Usahatani & Sangat Tinggi & $12,7-15$ & 2 & 4,00 \\
\hline & & Tinggi & $10,3-12,6$ & 27 & 54,00 \\
\hline & & Sedang & $7,9-10,2$ & 14 & 28,00 \\
\hline & & Rendah & $5,5-7,8$ & 7 & 14,00 \\
\hline & & Sangat Rendah & $3-5,4$ & 0 & 0,00 \\
\hline \multirow[t]{5}{*}{6.} & Pengalaman Berusahatani & Sangat Tinggi & $8,5-10$ & 0 & 0,00 \\
\hline & & Tinggi & $6,9-8,4$ & 4 & 8,00 \\
\hline & & Sedang & $5,3-6,8$ & 3 & 6,00 \\
\hline & & Rendah & $3,7-5,2$ & 43 & 86,00 \\
\hline & & Sangat Rendah & $2-3,6$ & 0 & 0,00 \\
\hline
\end{tabular}

Sumber: Data primer, 2016.

Berdasarkan Tabel 2 dapat diketahui bahwa distribusi tingkat pendidikan non formal petani secara keseluruhan termasuk dalam kategori sedang (80\%) yang artinya minat dan kesadaran petani terhadap kegiatan pelatihan maupun penyuluhan tergolong cukup baik. Petani mengikuti penyuluhan sebanyak 4 kali dalam satu musim tanam. Kegiatan penyuluhan yang dilaksanakan rutin oleh PPL untuk setiap kelompok tani biasanya 1 kali dalam 1 bulan dan waktunya disesuaikan dengan kesepakatan bersama antara petani dengan penyuluh. Sedangkan untuk kegiatan pelatihan, petani hanyak mengikuti pelatihan sebanyak 2 kali dalam satu kali masa tanam. Pelatihan diadakan untuk menunjang keterampilan petani dalam kegiatan GP-PTT. Pelatihan yang diberikan mengenai kegiatan pembuatan pupuk organik dan pembuatan obat-obatan organik.

Berdasarkan Tabel 2 dapat diketahui bahwa distribusi tingkat pendapatan petani secara keseluruhan termasuk dalam kategori tinggi (54\%). Petani memiliki pendapatan yang tinggi untuk usahatani padi dan kedelai. Petani memiliki rata-rata pendapatan $6-7,5$ juta per satu musim tanam. Pendapatan dari usahatani padi ini diperoleh dari penerimaan dikurangi biaya produksi. Sedangkan untuk usahatani kedelai rata-rata pendapatan petani antara 3,9-4,8 juta per satu musim tanam. Pendapatan yang didapat dari usahatani kedelai ini merupakan pendapatan bersih karena petani tidak mengeluarkan biaya pada saat melaksanakan kegiatan GP-PTT. Kemampuan petani untuk mencukupi kebutuhan keluarga tergolong tinggi yaitu 
petani mampu untuk mencukupi kebutuhan pokok sehari-hari dan terkadang juga dapat menabung. Hal ini membuktikan bahwa dengan adanya GP-PTT biaya produksi kedelai dapat dikurangi sehingga petani memperoleh pendapatan yang tinggi dan mampu mencukupi kebutuhan keluarga.

Berdasarkan Tabel 2 dapat diketahui bahwa distribusi luas lahan secara keseluruhan termasuk dalam kategori tinggi (54\%). Responden sebagian besar memiliki luas lahan antara $0,4-0,5$ ha dan seluruhnya digunakan untuk berbudidaya kedelai. Status kepemilikan lahan yang digunakan merupakan lahan milik sendiri dengan pemiliknya sebagai penggarap, tidak ada yang menyewa atau menyakap. Hal ini dikarenakan syarat utama penerima bantuan saprodi untuk GP-PTT adalah petani penggarap lahan miliknya sendiri atau petani penggarap lahan sewa.

Berdasarkan Tabel 2 dapat diketahui bahwa distribusi pengalaman berusahatani secara keseluruhan termasuk dalam kategori rendah (86\%). Petani mengusahakan budidaya tanaman kedelai selama antara 6 sampai 10 tahun. Hal ini disebabkan distribusi umur petani di Kecamatan Kedawung yaitu antara umur 55 - 60 tahun. Petani berumur sekitar 45 tahun ke atas ketika memulai usahatani kedelai. Petani memiliki status sebagai anggota aktif di tingkat kelompok tani. Status petani sebagai anggota aktif sangat berperan dalam kegiatan GP-PTT karena akan menambah pengalaman petani dan motivasi dalam mengikuti kegiatan tersebut.

\section{Partisipasi Petani dalam GP-PTT Kedelai}

Berdasarkan Tabel 3 dapat diketahui bahwa partisipasi petani pada tahap perencanaan kegiatan GP-PTT kedelai sebagian besar dalam kategori tinggi yaitu sebanyak 40 responden $(80 \%)$. Hal ini berarti bahwa responden mengetahui dan memahami sebagian tujuan dari GP-PTT kedelai. Selain itu petani juga mengikuti sosialisasi perencanaan yang diadakan sebelum kegiatan GP-PTT kedelai dimulai. Kegiatan sosialisasi itu meliputi pengenalan terhadap kegiatan GPPTT kedelai, proses pemberian dan penyaluran dana bantuan sosial, pencatatan calon penerima bantuan sosial, penyusunan Rencana Usaha Kelompok (RUK) untuk proses pencairan dana. Dalam sosialisasi perencanaan, petani juga dilibatkan dalam pengajuan ide/gagasan ataupun pertanyaan. 
Tabel 3. Partisipasi petani dalam GP-PTT kedelai

\begin{tabular}{|c|c|c|c|c|c|}
\hline No. & Tingkat Partisipasi & Kategori & Interval & $\begin{array}{c}\text { Jumlah } \\
\text { Responden }\end{array}$ & $\begin{array}{c}\text { Prosentase } \\
(\%)\end{array}$ \\
\hline \multirow[t]{7}{*}{1.} & Perencanaan & Sangat & $29,50-35,00$ & 0 & 0,00 \\
\hline & & Tinggi & $23,90-29,40$ & 40 & 80,00 \\
\hline & & Tinggi & $18,30-23,80$ & 10 & 20,00 \\
\hline & & Sedang & $12,70-18,20$ & 0 & 0,00 \\
\hline & & Rendah & $7,00-12,60$ & 0 & 0,00 \\
\hline & & Sangat & & & \\
\hline & & Rendah & & & \\
\hline \multirow[t]{7}{*}{2.} & Pelaksanaan & Sangat & $67,30-80,00$ & 22 & 44,00 \\
\hline & & Tinggi & $54,50-67,20$ & 28 & $\mathbf{5 6 , 0 0}$ \\
\hline & & Tinggi & $41,70-54,40$ & 0 & 0,00 \\
\hline & & Sedang & $28,90-41,60$ & 0 & 0,00 \\
\hline & & Rendah & $16,00-28,80$ & 0 & 0,00 \\
\hline & & Sangat & & & \\
\hline & & Rendah & & & \\
\hline \multirow[t]{7}{*}{3 . } & Pemantauan dan Evaluasi & Sangat & $33,70-40,00$ & 0 & 0,00 \\
\hline & & Tinggi & $27,30-33,60$ & 6 & 12,00 \\
\hline & & Tinggi & $20,90-27,20$ & 44 & 88,00 \\
\hline & & Sedang & $14,50-20,80$ & 0 & 0,00 \\
\hline & & Rendah & $8,00-14,40$ & 0 & 0,00 \\
\hline & & Sangat & & & \\
\hline & & Rendah & & & \\
\hline \multirow[t]{7}{*}{4.} & Pemanfaatan Hasil & Sangat & $22,00-25,00$ & 0 & 0,00 \\
\hline & & Tinggi & $18,00-21,00$ & 11 & 22,00 \\
\hline & & Tinggi & $14,00-17,00$ & 39 & 78,00 \\
\hline & & Sedang & $10,00-13,00$ & 0 & 0,00 \\
\hline & & Rendah & $5,00-9,00$ & 0 & 0,00 \\
\hline & & Sangat & & & \\
\hline & & Rendah & & & \\
\hline
\end{tabular}

Sumber: Data primer, 2016.

Berdasarkan Tabel 3 dapat diketahui bahwa partisipasi petani pada tahap pelaksanaan kegiatan GP-PTT kedelai sebagian besar dalam kategori tinggi yaitu sebanyak 28 responden (56\%). Tahap pelaksanaan ini diukur dari keaktifan responden dalam mengikuti kegiatan pembibitan, pengolahan media tanam, teknik penanaman, pemeliharaan tanaman, pengendalian Organisasi Pengganggu Tanaman (OPT), dan pengelolaan pasca panen. Partisipasi petani terhadap tahap pelaksanaan termasuk dalam kategori tinggi, hal ini dikarenakan petani mengikuti kegiatan tersebut sesuai dengan pedoman serta didampingi oleh penyuluh dalam melakukan kegiatan penanaman.

Berdasarkan Tabel 3 dapat diketahui bahwa partisipasi petani pada tahap pemantauan dan evaluasi kegiatan GP-PTT kedelai sebagian besar dalam kategori sedang yaitu sebanyak 44 responden $(88 \%)$. Hal ini dikarenakan, rapat evaluasi diadakan sebanyak 4 kali setelah pelaksanaan kegiatan namun petani hanya menghadiri rapat evaluasi sebanyak 2 kali. Melalui rapat evaluasi, petani diberi kesempatan untuk mengajukan kritik/saran terkait pelaksanaan GP-PTT kedelai yang telah dilaksanakan. Selain rapat evaluasi, yang dijadikan acuan dalam evaluasi kegiatan GP-PTT kedelai adalah minat dan penilaian petani terhadap kegiatan tersebut.

Hubungan Karakteristik Sosial Ekonomi Petani dengan Partisipasi Petani dalam GPPTT Kedelai

Berdasarkan Tabel 3 dapat diketahui bahwa partisipasi petani pada tahap pemanfaatan hasil kegiatan GP-PTT kedelai sebagian besar dalam kategori sedang yaitu sebanyak 39 responden (78\%). Pengaruh kegiatan GP-PTT kedelai dalam peningkatan keterampilan dan pengetahuan, serta peningkatan pendapatan dan peningkatan 
produktivitas kedelai termasuk dalam kategori sedang, yaitu hanya berpengaruh sekitar $20 \%$ $30 \%$. Sedangkan keinginan petani untuk meneruskan kegiatan GP-PTT kedelai termasuk dalam kategori sangat tinggi, yaitu $80 \%-100 \%$. Hal ini dikarenakan kegiatan GPPTT kedelai sangatlah bermanfaat bagi petani.

Tabel 4. Hubungan karakteristik sosial ekonomi petani dengan partisipasi petani dalam GP-PTT kedelai

\begin{tabular}{ccccccccccc}
\hline \multirow{2}{*}{ Var } & \multicolumn{2}{c}{ Y1 } & \multicolumn{2}{c}{ Y2 } & \multicolumn{2}{c}{ Y3 } & \multicolumn{2}{c}{ Y4 } & \multicolumn{2}{c}{ Y tot } \\
\cline { 2 - 11 } & Rs & Thit & Rs & Thit & rs & Thit & rs & Thit & Rs & Thit \\
\hline X1 & 0,097 & 0,672 & $-0,257$ & $-1,778$ & 0,186 & 1,288 & $-0,243$ & $-1,681$ & 0,079 & 0,547 \\
X2 & 0,238 & 1,647 & $-0,151$ & $-1,046$ & 0,146 & 1,011 & $-0,138$ & $-0,956$ & 0,143 & 0,99 \\
X3 & $0,608^{* *}$ & $\mathbf{4 , 1 6 1}$ & $-0,36$ & $-0,249$ & $0,370^{* *}$ & $\mathbf{2 , 5 5 5}$ & $-0,143$ & $-0,99$ & $0,424^{* *}$ & $\mathbf{2 , 9 2 4}$ \\
X4 & 0,128 & 0,887 & $-0,178$ & $-1,232$ & $-0,241$ & $-1,668$ & $-0,028$ & $-1,936$ & $-0,112$ & 0,776 \\
X5 & 0,172 & 1,191 & $-0,236$ & $-1,633$ & $-0,287 * *$ & $-1,985$ & 0,003 & 0,021 & $-0,153$ & 1,059 \\
X6 & $0,560^{* *}$ & $\mathbf{3 , 8 4 3}$ & 0,037 & 0,256 & 0,168 & 1,163 & 0,053 & 0,367 & $0,327 * *$ & $\mathbf{2 , 2 6 0}$ \\
Xtot & $0,284^{*}$ & 1,964 & $-0,217$ & $-1,502$ & 0,114 & $-0,79$ & $-0,93$ & $-0,644$ & 0,012 & 0,083 \\
\hline
\end{tabular}

Sumber: Analisis data primer, 2016.

Keterangan:

** : signifikan pada $\alpha=0,01$,

* : signifikan pada $\alpha=0,05, \mathrm{t}$ tabel: $2,011(\alpha=0,05)$, rs: Koefisien korelasi Spearman, X1: Umur, X2: Pendidikan Formal, X3: Pendidikan Non Formal, X4: Pendapatan, X5: Luas Usahatani, X6: Pengalaman Berusahatani, Xtot: Karakteristik Sosial Ekonomi, Y1: Partisipasi dalam perencanaan, Y2: Partisipasi dalam pelaksanaan, Y3: Partisipasi dalam pemantauan dan evaluasi, Y4: Partisipasi dalam pemanfaatan hasil, Ytot: Partisipasi petani dalam GP-PTT Kedelai.

Hasil Penelitian menunjukkan bahwa: (1) Terdapat hubungan yang sangat signifikan antara pendidikan non formal dengan tingkat partisipasi pada tahap perencanaan. Hal itu dikarenakan semakin tinggi pendidikan nonformal petani maka semakin banyak kegiatan penyuluhan dan pelatihan yang diikuti sehingga petani memperoleh pengetahuan dan pengalaman dalam merencanakan suatu kegiatan. Petani yang memiliki pendidikan non formal yang tinggi dapat memberikan dampak yang baik terhadap kegiatan GP-PTT. Hal ini dikarenakan petani tersebut dapat memberikan arahan dan masukan kepada petani yang memiliki pendidikan non formal rendah, sehingga dapat membantu memperlancar tahap perencanaan, (2) Terdapat hubungan yang sangat signifikan antara pendidikan non formal dengan tingkat partisipasi pada tahap pemantauan dan evaluasi karena salah satu komponen fasilitas dalam kegiatan GP-PTT adalah kegiatan penyuluhan dalam pertemuan kelompok, sehingga melalui pertemuan tersebut petani dapat menyampaikan ide/gagasan serta memaparkan evaluasi dari pelaksanaan yang telah ditempuh. Petani yang memiliki pendidikan non formal yang tinggi akan cenderung selalu memberikan ide/gagasannya agar kegiatan GP-PTT dapat berjalan lancar dan lebih baik, dan (3) Terdapat hubungan yang sangat signifikan antara pengalaman berusahatani dengan tingkat partisipasi pada tahap perencanaan. Hubungan yang signifikan ini dikarenakan pengalaman petani dilihat dari lamanya petani berusahatani kedelai dapat memberikan pengetahuan dan keterampilan dalam perencanaan kegiatan sehingga mempengaruhi partisipasi petani dalam tahap perencanaan. Petani yang memiliki pengalaman yang lebih banyak akan menyumbangkan ide/gagasannya dalam sosialisasi perencanaan sehingga kegiatan GP-PTT dapat berjalan sesuai rencana.

\section{KESIMPULAN}

Berdasarkan penelitian dan pembahasan, maka dapat ditarik kesimpulan sebagai berikut: (1) Karakteristik sosial ekonomi petani: Umur petani dengan presentase $44 \%$ mayoritas tergolong rendah, pendidikan formal petani dengan presentase $42 \%$ mayoritas tergolong rendah, pendidikan non formal petani dengan presentase $80 \%$ mayoritas tergolong sedang, pendapatan petani yang diperoleh dari hasil usahatani dengan presentase $54 \%$ mayoritas tergolong tinggi, luas usahatani yang digunakan petani untuk 
kegiatan GP-PTT dengan presentase 54\% mayoritas tergolong sedang, pengalaman berusahatani yaitu lamanya petani berusahatani kedelai dengan presentase $80 \%$ mayoritas tergolong rendah, (2) Partisipasi petani dalam GP-PTT: Partisipasi pada tahap perencanaan mayoritas tergolong kategori tinggi dengan presentase $80 \%$, partisipasi pada tahap pelaksanaan mayoritas tergolong kategori tinggi dengan presentase 56\%, partisipasi pada tahap pemantauan dan evaluasi mayoritas tergolong kategori sedang dengan presentase $88 \%$, partisipasi pada tahap pemanfaatan hasil mayoritas tergolong kategori sedang dengan presentase $78 \%$, dan (3) Terdapat hubungan yang sangat signifikan antara pendidikan non formal dengan tingkat partisipasi pada tahap perencanaan dan tahap pemantauan dan evaluasi. Terdapat hubungan yang sangat signifikan antara Terdapat hubungan yang sangat signifikan antara pendidikan non formal dengan tingkat partisipasi pada tahap perencanaan dan tahap pemantauan dan evaluasi. Terdapat hubungan yang sangat signifikan antara pengalaman berusahatani dengan tingkat partisipasi pada tahap perencanaan.
Sehubungan dengan kesimpulan tersebut, selanjutnya dapat diberikan saran sebaiknya diadakan pertemuan rutin untuk melakukan pemantauan dan evaluasi terhadap kegiatan yang telah terlaksana, sehingga petani dapat menyampaikan pengalamannya setelah melaksanakan kegiatan GP-PTT kedelai.

\section{DAFTAR PUSTAKA}

Direktorat Jenderal Tanaman Pangan. 2015. Pedoman teknis GP-PTT kedelai 2015. Kementerian Pertanian.

Effendi dan Tukiran. 2012. Metode Penelitian Survei. LP3ES. Jakarta.

Mardikanto, T. 2006. Prosedur penelitian: untuk kegiatan penyuluhan pembangunan dan pemberdayaan masyarakat. Prima Theresia Pressindo. Surakarta.

Siegel, S. 1997. Statistik Non Parametrik. PT Gramedia. Jakarta.

Singarimbun, M dan S. Effendi. 2006. Metode Penelitian Survei. LP3ES. Jakarta.

Wiwik dan Herliswanny. 1998. Partisipasi masyarakat di pedesaan sumatra selatan. CV. Bupara Nugraha. Jakarta. 